\title{
Phase 1 clinical trial demonstrated that MUC1 positive metastatic seminal vesicle cancer can be effectively eradicated by modified Anti-MUC1 chimeric antigen receptor transduced $\mathbf{T}$ cells
}

\author{
Fengtao You ${ }^{1,2,3}$, Licui Jiang ${ }^{2,3}$, Bozhen Zhang ${ }^{2,3}$, Qiang Lu ${ }^{4}$, Qiao Zhou ${ }^{4}$, Xiaoyang Liao, \\ Hong $\mathrm{Wu}^{4}$, Kaiqi $\mathrm{Du}^{5}$, Youcai Zhu ${ }^{5}$, Huimin Meng ${ }^{1}$, Zhishu Gong ${ }^{6}$, Yunhui Zong ${ }^{2,3}$, \\ Lei Huang ${ }^{2,3}$, Man Lu ${ }^{2,3}$, Jirong Tang ${ }^{2,3}$, Yafen $\mathrm{Li}^{2,3}$, Xiaochen Zhai ${ }^{7}$, Xiangling Wang ${ }^{7}$, \\ Sisi Ye ${ }^{2,3}$, Dan Chen ${ }^{2,3}$, Lei Yuan ${ }^{8}$, Lin $\mathrm{Qi}^{2,3}$ \& Lin Yang ${ }^{1,2,3,7^{*}}$ \\ ${ }^{1}$ The Cyrus Tang Hematology Center; Collaborative Innovation Center of Hematology, Soochow University, Suzhou 215123, China; \\ ${ }^{2}$ Suzhou Cancer Immunotherapy and Diagnosis Engineering Center, Suzhou 215123, China; \\ ${ }^{3}$ Persongen Biomedicine (Suzhou) Co., Ltd, Suzhou 215123, China; \\ ${ }^{4}$ West China Hospital, Sichuan University, Chengdu 610041, China; \\ ${ }^{5}$ Department of Cardiothoracic Surgery, Chinese People's Armed Police Force of Zhejiang Corps Hospital, Jiaxing 314000, China; \\ ${ }^{6}$ The Medical Group of Zhengzhou First People's Hospital, Zhengzhou 450004, China; \\ ${ }^{7}$ College of Pharmacy, Xi' an Jiaotong University, Suzhou 215123, China; \\ ${ }^{8}$ Department of Hematology, Chinese PLA General Hospital, Beijing 100853, China
}

Received December 26, 2015; accepted January 16, 2016; published online March 3, 2016

\begin{abstract}
Recent progress in chimeric antigen receptor-modified T-cell (CAR-T cell) technology in cancer therapy is extremely promising, especially in the treatment of patients with B-cell acute lymphoblastic leukemia. In contrast, due to the hostile immunosuppressive microenvironment of a solid tumor, CAR T-cell accessibility and survival continue to pose a considerable challenge, which leads to their limited therapeutic efficacy. In this study, we constructed two anti-MUC1 CAR-T cell lines. One set of CAR-T cells contained SM3 single chain variable fragment ( $\mathrm{scFv}$ ) sequence specifically targeting the MUC1 antigen and co-expressing interleukin (IL) 12 (named SM3-CAR). The other CAR-T cell line carried the SM3 scFv sequence modified to improve its binding to MUC1 antigen (named pSM3-CAR) but did not co-express IL-12. When those two types of CAR-T cells were injected intratumorally into two independent metastatic lesions of the same $\mathrm{MUC1}^{+}$seminal vesicle cancer patient as part of an interventional treatment strategy, the initial results indicated no side-effects of the MUC1 targeting CAR-T cell approach, and patient serum cytokines responses were positive. Further evaluation showed that pSM3-CAR effectively caused tumor necrosis, providing new options for improved CAR-T therapy in solid tumors.
\end{abstract}

MUC1, CAR-T therapy, solid tumor, seminal vesicle cancer

Citation: You, F., Jiang, L., Zhang, B., Lu, Q., Zhou, Q., Liao, X., Wu, H., Du, K., Zhu, Y., Meng, H., Gong, Z., Zong, Y., Huang, L., Lu, M., Tang, J., Li, Y., Zhai, X., Wang, X., Ye, S., Chen, D., Yuan, L., Qi, L., and Yang, L. (2016). Phase 1 clinical trial demonstrated that MUC1 positive metastatic seminal vesicle cancer can be effectively eradicated by modified Anti-MUC1 chimeric antigen receptor transduced T cells. Sci China Life Sci 59, 386-397. doi: 10.1007/s11427-016-5024-7

*Corresponding author (email: yanglin@ suda.edu.cn; lin.yang@ persongen.com) 


\section{INTRODUCTION}

T-cell based immunotherapy is becoming a hotspot of the cancer therapeutics area. Specifically, using gene transfer technologies, patient T-cells can be genetically modified to stably express single-chain variable fragments $(\mathrm{scFv})$ or ligands capable of binding antigens or receptors, respectively, to confer novel major histocompatibility complex (MHC) - independent antigen specificities on tumor cells. These structures are called chimeric antigen receptors (CARs) and contain three basic elements - the extracellular antigen binding domain, transmembrane domain, and cytoplasmic signaling domain. First-generation CARs featured a single signaling domain most commonly derived from the $\mathrm{CD} 3 \zeta$ component of TCR ( $\mathrm{T}$ cell receptor)/CD3 complex. Second- or third-generation CARs were designed by including additional signaling domains, such as CD28 and/or 4-1BB, that potentiate T-cell effector functions and activate co-stimulatory pathways, resulting in upregulation of genes encoding anti-apoptotic proteins and increased cytokine secretion. With this strategy, a complete remission among 30 children and adults who received CD19-targeting CAR-T cell therapy for relapsed or refractory acute lymphoblastic leukemia (ALL) was achieved with 90\% success rates (Porter et al., 2011, Davila and Brentjens, 2013; Grupp et al., 2013, Jensen and Riddell, 2014; Maude et al., 2014, 2015; Pegram et al., 2014; Turtle, 2014; Condomines et al., 2015; Jonnalagadda et al., 2015).

In solid tumor therapy, CAR-T cells showed little therapeutic efficacy for the following reasons: (i) off-target toxicity due to the expression of target antigens in normal tissue; (ii) heterogeneity of tumor lesions with the target-negative tumor cells ultimately becoming the dominant population, and most importantly; (iii) release of immune repressive cytokines, such as transforming growth factor (TGF) $\beta$ and interleukin (IL) 10 , by tumor cells, and presence of suppressive cells, such as regulatory T-cells (tregs) and tumor-associated macrophages (TAMs), etc., creating an immunosuppressive microenvironment encasing the tumor cells and significantly inhibiting CAR-T cell homing abilities (Kakarla and Gottschalk, 2014; Lamers et al., 2014; Abken, 2015; Hillerdal and Essand, 2015). Accordingly, some research groups have engineered IL-12 co-expressed CAR-T-cells at the tumor foci to suppress the unfavorable tumor microenvironment. IL-12 is a heterodimeric inflammatory cytokine produced by activated antigen-presenting cells (APCs), neutrophils, and macrophages, that also induces Th1 CD4 ${ }^{+}$T-cell response. IL-12 can serve as signal 3 , in concert with TCR activation (signal 1) and CD28 costimulation (signal 2) of $\mathrm{CD}^{+} \mathrm{T}$-cells, resulting in optimized clonal expansion and effector function. IL-12 induces proliferation and cytotoxic activity of natural killer (NK) cells and generates anti-tumor activity through the effector cell-produced cytokines, including interferon-gamma (INF- $\gamma$ ), which in turn upregulate tumor cell Fas (CD95) and FasL. More significantly, IL-12 has been shown to modulate the hostile tumor microenvironment through multiple mechanisms, including reactivation of anergic tumor-infiltrated lymphocytes (TILs), inhibition of Treg-mediated suppression of the effector T-cells, recruitment of NK cells to the tumor site, and inhibition of TAM IL-10 and transforming growth factor- $\beta$ (TGF- $\beta$ ) secretion (Chinnasamy et al., 2012; Chmielewski et al., 2014; Chmielewski and Abken, 2015; Pegram et al., 2015).

Appropriate tumor targets need to be identified to minimize the off-target effect of CAR-T cells. Mucin 1 (MUC1) is becoming an interesting target in cancer immunotherapy, for three reasons. First, aberrant expression of MUC1 has been reported in most solid tumors and many hematologic malignancies (Kruger et al., 2000; Jonckheere and Van Seuningen, 2010). Second, whereas MUC1 is normally confined to the luminal epithelium, this polarity of expression is lost upon malignant transformation. Third, glycosylation of MUC1 is largely deregulated in cancer. Owing to an altered glycosyltransferase expression, tumor-associated MUC1 is decorated by a preponderance of shorter glycans, including Thomsen-nouveau (Tn), sialyl Tn (STn), ThomsenFriedenreich (T), and sialyl-T (ST). Under-glycosylation of MUC1 unmasks cryptic epitopes within the extracellular domain containing a variable number of tandem repeats (VNTR), enabling tumor-selective binding by several antibodies (Abs) (Acres and Limacher, 2005; Yang et al., 2007; Tang and Apostolopoulos, 2008; Tang et al., 2008; Beatson et al., 2010; Kimura and Finn, 2013; Madsen et al., 2013; Acres et al., 2015). Some research groups recently reported their efforts in developing MUC1-CAR-T cells, in which SM3 scFv, a renowned antibody with tumor-associated

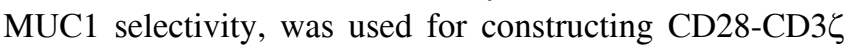
CAR. However, the resultant SM3-CD28-CD3 $\zeta$ CAR proved extremely poor in retargeting human T-cells toward a variety of MUC1-expressing tumor cells. These disappointing results illustrated the existence of two types of steric inhibition, one imposed by the large size of immobilized MUC1 and the other by its heterogeneous glycosylation. The precise binding properties of SM3 to tumor-associated MUC1 were then analyzed and found to be suboptimal. In particular, SM3 did not bind to MUC1-ST, which is widely expressed by many tumor cells. Another anti-MUC1 scFv, of HMFG2, was identified, differing from SM3 by five amino acids and exhibiting a 7.4-fold-higher affinity for unglycosylated MUC1, which was sufficient to enable T-cells grafted with this CAR to proliferate robustly when plated on anchored glycan-free MUC1. Accordingly, HMFG2-CD28-OX40-CD3z CAR was tested in a preclinical model, which resulted in a significant delay of tumor growth (Wilkie et al., 2008; Maher and Wilkie, 2009; Gheybi et al., 2014).

No clinical trial has been reported to date for MUC1-targeting CAR-T therapy. Here, we present a case report from a first-in-human study of MUC1-specific 
CAR-T cells in a patient with MUC1-expressing seminal vesicle cancer. In order to reduce the off-target effect of CAR-T cells and overcome the immune suppressive microenvironment of tumor foci, we constructed two MUC1CAR-T platforms. One platform comprised SM3-CD28CD137-IL12 CAR (SM3-CAR), and the other pSM3-CD28CD137 CAR (pSM3-CAR) with a mutated SM3 scFv sequence to improve SM3 binding to MUC1 ST glycans. In addition, we incorporated a novel strategy of CAR-T cell delivery, intratumoral injection. Consequently, we obtained clinical evidence of tumor responses with pSM3-CAR. Our data thus support the feasibility of pSM3-CAR-T cell approach, in combination with an interventional treatment, as a novel strategy for the treatment of patients with $\mathrm{MUC1}^{+}$ solid malignancies, and suggest therapeutic benefits of pSM3-CAR-T cells.

\section{RESULTS}

\section{Preclinical analysis}

One metastatic seminal vesicle cancer patient was enrolled in the trial. Before we recruited him into the program, biopsies from pleural and intraperitoneal metastases (cell smears and tissue sections) from this patient was stained for MUC1 expression. Notably, strong MUC1 expression was observed (Figure 1A and B), more pronounced in the biopsy material than in MUC1-positive MCF7 control cells. To further verify MUC1 positivity, primary tumor cells were also assessed by western-blot and flow cytometry assays. Consistently, the tumor cells were also highly MUC1 positive (Figure 1C and D). Immunohistochemistry confirmed MUC1 expression in patient tumor biopsies (data not shown). We therefore concluded that, for this patient, MUC1 can be used as a CAR-T cell therapy antigen.

\section{Anti-MUC1-CAR design}

In general, the $\mathrm{scFv}$ fragment contributes to new antigen specificity of a CAR-T cell, whereas intracellular CAR signaling domains are responsible for the functional outcome of CAR-mediated T-cell activation. MUC1 is commonly over-expressed in tumors and it has been predicted to be a potential target of immune therapy in about $80 \%$ of all cancer cases (Acres and Limacher, 2005). It is, however, also expressed in normal tissues, albeit as a different glycoform (Wilkie et al., 2008). Accordingly, the scFv sequence for CAR construction had to be very carefully selected. MUC1-specific monoclonal antibodies (MAbs) distinguish healthy MUC1 from cancer-associated MUC1 (Kimura and Finn, 2013; Madsen et al., 2013). This is supported by evidence from the Joyce Taylor-Papadimitriou laboratory, who showed in a series of excellent experiments that antibodies targeting the human milk fat protein mucin-1 chemically stripped of its carbohydrate side chains specifically reacted with the cancer-associated MUC1 glycoprotein (Gendler et al., 1991; Taylor-Papadimitriou et al., 1993). This suggested that cancer associated MUC1 is non- or at least under-glycosylated in comparison with the normal MUC1 glycoprotein. Among the characterized MUC1 antibodies, clone SM3 is renowned for its selectivity against tumor-associated MUC1 (Granowska et al., 1990; Burchell and Taylor-Papadimitriou, 1993; Granowska et al., 1993; Wilkie et al., 2008), we therefore first constructed SM3 scFv-based CAR with IL-12 co-expression (SM3-CAR). Because it has been reported that 4-1BB domain may enhance CAR-T cell persistence, our final version of SM3-CAR contained SM3 scFv fused to sequences derived from $\mathrm{CD} 28,4-1 \mathrm{BB}$, and $\mathrm{CD} 3 \zeta$, followed by an internal ribosome entry site (IRES)-controlled IL-12 sequence (Figure 2A).
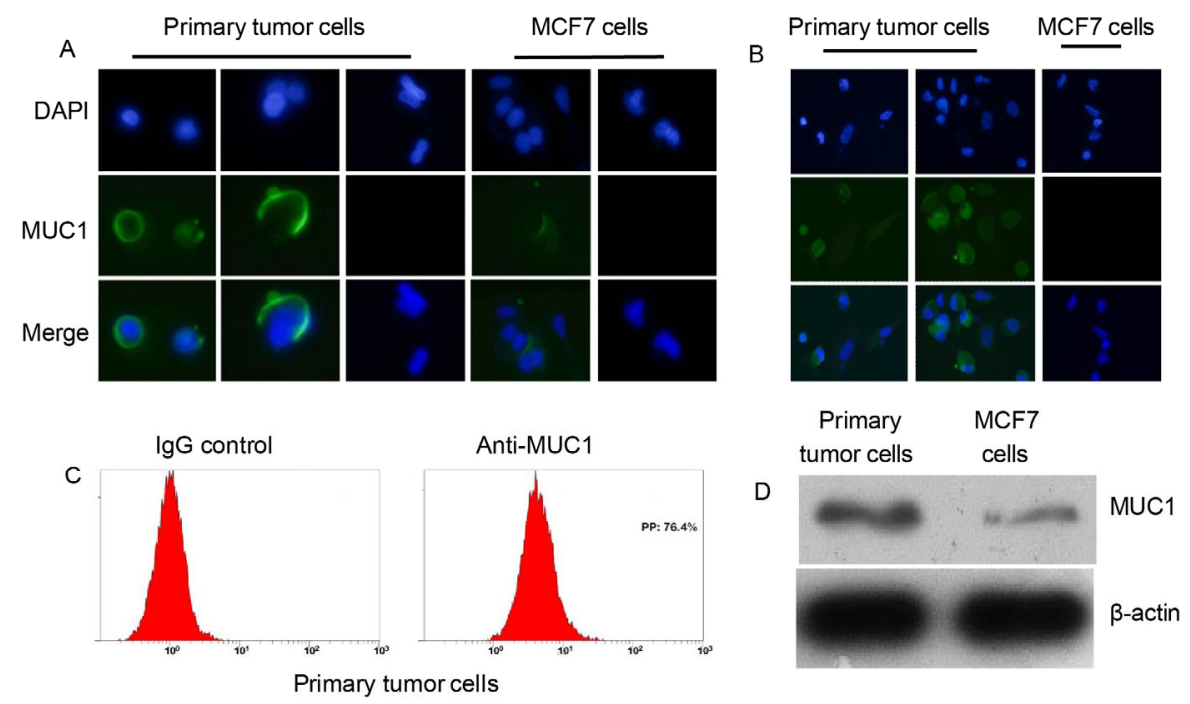

Figure 1 MUC1 expression in patient tumor biopsies. A, Immunostaining of patient primary tumor cells for surface MUC1 expression. MUC1 ${ }^{+}$MCF7 cells were used as positive control. B. Immunostaining of patient primary tumor cells for intracellular MUC1 expression. MUC1 ${ }^{+} \mathrm{MCF}$ cells were used as positive control. C, Flow cytometry assay was used to detect MUC1 expression on patient primary tumor cells. D, Western-blot was performed to detect MUC1 expression in patient primary tumor cells and MCF7 cells respectively. 


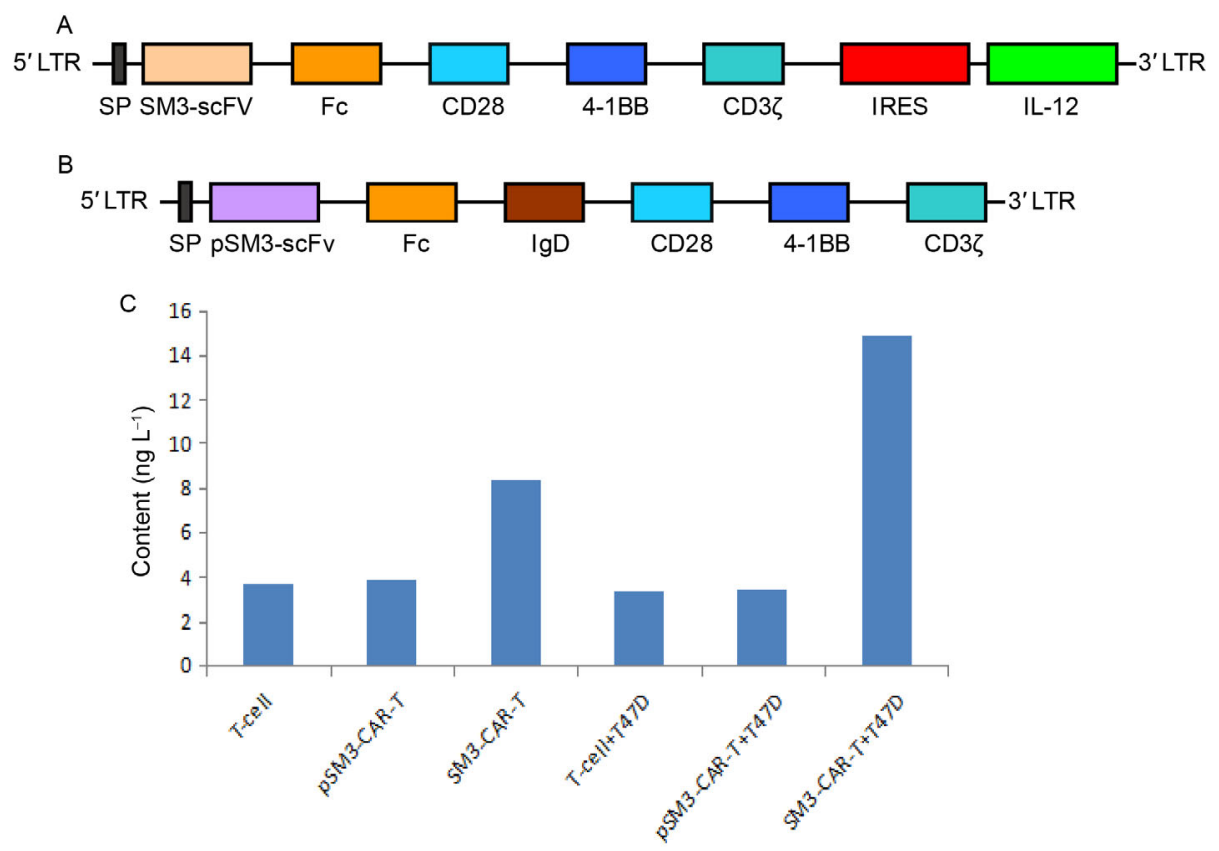

Figure 2 Schematic illustration of the MUC1 specific CAR. A, SM3-CAR consists of a signal peptide (SP), SM3 scFv as an extracellular domain, an Fc domain, a CD28 transmembrane domain, and an intracellular signal transduction domain CD3-z, followed by IRES driven IL-12 molecules. B, pSM3-CAR includes a mutated SM3 scFv in which six amino acids were changed to improve its binding ability to tumor associated MUC1. In addition, pSM3-CAR contains a IgD hinge fragment to increase its flexibility. In contrast to SM3-CAR, pSM3-CAR has no IRES driven IL-12 molecules. C, Expression of IL-12 in condition medium of SM3-CAR-T cells co-cultured with/without MUC1 ${ }^{+}$T47D cells was examined by the enzyme-linked immunosorbent assay (ELISA).

\section{SM3 scfv mutation improves tumor-associated MUC1 binding capacity}

Since SM3 scFv-derived CAR was extremely poor in retargeting human T-cells against a variety of MUC1-expressing tumor cells, we were concerned that our new SM3-CAR may lead to disappointing clinical outcomes regardless of the inclusion of IL-12. Recent studies by the Maher group suggested that $\mathrm{scFv}$ sequence cloned from HMFG2 hybridoma formed against MUC1 exhibited superior binding to tumor-associated MUC1, especially when the CAR comprised an IgD hinge fragment that provided greater flexibility and access to the epitope, thereby overcoming steric inhibition (Wilkie et al., 2008). Based on these findings, we mutated six amino acids in the SM3 scFv sequence. The mutated form of SM3 scFv (pSM3 scFv) was fused to the Fc domain and IgD hinge fragment, and used to construct

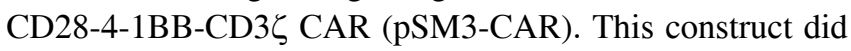
not contain IL-12 (Figure 2B).

\section{Characterization of MUC1-CAR-T cells}

Lentiviral SM3-CAR and pSM3 particles were prepared as described in Materials and methods. Thirty MOI (multiplicity of infection) suspensions of SM3-CAR or pSM3-CAR lentiviruses, $1 \times 10^{8} \mathrm{~mL}^{-1}$ titers, were used to separately transduce the patient's T-cells. Flow cytometry assays indicated similar transduction efficiencies for the two CARs, and $21 \%$ and $18 \%$ of SM3-CAR-T- and pSM3-CAR-Tpositive cells, respectively, were observed (data not shown).
A series of in vitro immunology assays was used to further evaluate the constructs. Cytotoxicity assays were used to evaluate SM3-CAR-T cells against T47D cells, an endogenous MUC1-expressing tumor cell line (data not shown). Untransduced $\mathrm{T}$ cells and CD19-CAR lentiviral vector transduced $\mathrm{T}$ cells were served as negative control (Figure $3 \mathrm{~A}$ and $\mathrm{B}$ ), which showed basic cytolytic activity toward T47D cells ( $15 \%$ and $21 \%$ respectively) with a $\mathrm{E}: \mathrm{T}$ ratio (effector:target) of 30:1. In contrast, SM3-CAR-T cells and pSM3-CAR-T cells had greater cytolytic activity toward T47D cells. As shown in Figure 3C and D, when $\mathrm{E}: \mathrm{T}$ ratio was 30:1, SM3-CAR-T and pSM3-CAR-T cells killed T47D cells up to $44 \%$ and $51 \%$ respectively.

\section{Clinical antitumor response of MUC1-CAR-T cells}

After SM3-CAR-T cells and pSM3-CAR-T cells were injected into two separate tumor lesions respectively and simultaneously as described in Materials and methods, we monitored the patient's responses as frequently as possible since we employed an interventional treatment strategy in this study. The patient began to suffer from mild headache, muscle pain, nasal congestion, and mild abdominal bloating discomfort, but with normal breath, blood pressure, pulse, and oxygen saturation, one day after the intratumoral injection. The patient's basal body temperature was $36.1^{\circ} \mathrm{C}$ before the initiation of CAR-T therapy, and increased to $38.2^{\circ} \mathrm{C}$ on third day post-injection, implying a positive response to the therapy (Figure 4A). From the sixth to twelfth 

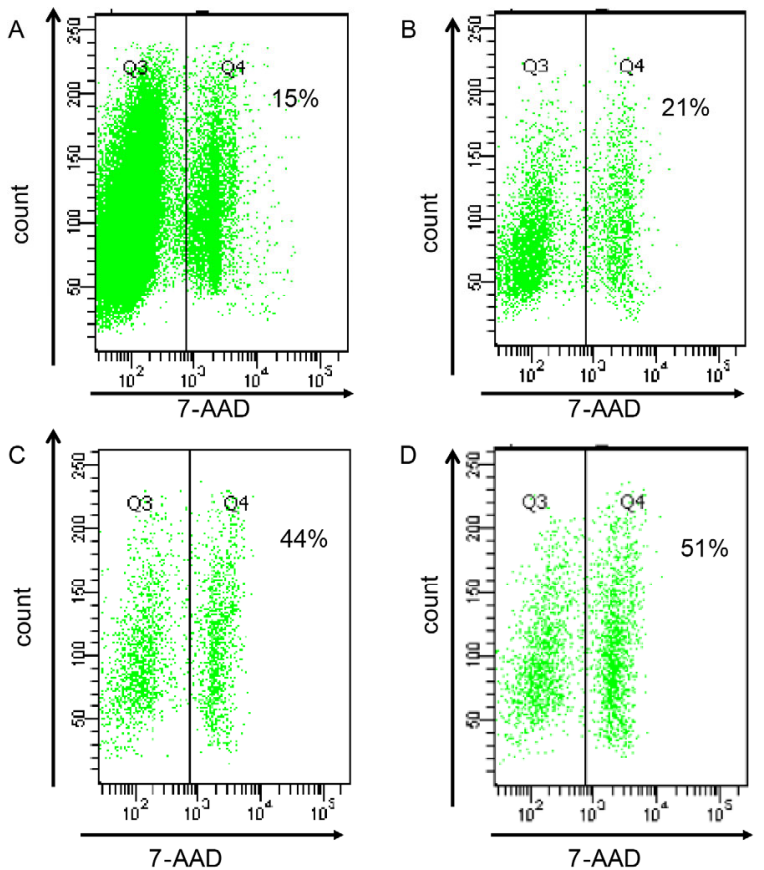

Figure 3 (color online) Cytotoxicity assays of MUC1 targeted CAR-T cells against MUC1 positive cells of T47D in vitro. A, Non-transduced T cells. B, CD19-CAR lentiviral vector transduced T cells. C, SM3-CAR-T cells $(\mathrm{E}: \mathrm{T}=30: 1)$. D, pSM3-CAR-T cells $(\mathrm{E}: \mathrm{T}=30: 1)$; T47D cells were incubated with CAR T cells or control $\mathrm{T}$ for $24 \mathrm{hrs}$. Lysis of the tumor cells was quantified using 7-AAD assay.

day post the intratumoral injection, all discomforts disappeared and the body temperature returned to normal. However, started from $13^{\text {th }}$ day of post-intratumoral injection, patient experienced 1-3 times of loose stools daily for two days with a paste shape, although the stool color was normal. And at the $15^{\text {th }}$ day of post-intratumoral injection, there were blood found three times in the stools after the patient drinking cleaning fluid intestinal phosphate.

The patient's blood analysis indicated some abnormalities, including increased eosinophil ratio and counts, and elevated glucose levels (Table 1), suggesting an inflammatory response, or an acute response. In comparison with the basal uric acid levels, which were within normal range (Table 1), the patient's uric acid levels post injection increased, implying a possible minor kidney dysfunction.

The patient was examined to evaluate the impact of
CAR-T cell treatment on immune activation. This was accomplished by soluble immune-factor profiling of serum samples collected at defined time points. IL-6 and tumor necrosis factor alpha (TNF- $\alpha$ ) were determined, as well as CRP (C reaction protein), which has been reported to be associated with IL-6 expression (Barrett et al., 2014). A transient cytokine release syndrome, with a 10 folds increase of IL-6 and ca. $60 \%$ increase of TNF- $\alpha$ levels, was detected after intratumoral injection. The cytokines remained elevated for $21 \mathrm{~d}$, until biopsies of the treated tumor were surgically analyzed. Larger increases of CRP levels were observed on the second and third day post- intratumoral injection, and remained elevated (Figure 4B). Although it is not clear from the cytokine data whether this effect was due to SM3-CAR-T cells or pSM3-CAR-T cells, at least some CAR-T cells triggered the patient's immune response.

To fully evaluate the therapeutic efficacy of CAR-T cells and determine if SM3-CAR-T or pSM3-CAR-T cells benefit the patient better, ultrasonographic images were taken at the 21st day of post-intratumoral injection, followed by a surgical resection of the tumors. Unfortunately, SM3-CART tumor showed little necrosis (image data not shown), indicating that SM3-CAR-T cells failed to recognize tumor cells even IL-12 was co-expressed. In contrast, pSM3-CART-treated tumor had two necrotic areas, including an old necrotic area, which might have been caused by a previous hypoxia, and a new necrotic area, which perfectly matched the sites of pSM3-CAR-T cell injections (Figure 5). This indicated that mutating SM3 scFv may indeed have improved binding to tumor-associated MUC1 and, consequently, tumor cell killing.

Furthermore, tumor biopsies were analyzed by immunohistochemistry assay. As shown in Table 2, SM3-CAR-T tumor and pSM3-CAR-T tumor both have infiltrated $\mathrm{CD}^{+}$ $\mathrm{T}$ cells, as well as $\mathrm{CD}^{+} / \mathrm{CD}^{+} \mathrm{T}$ cells, suggesting the persistence of intratumorally injected $\mathrm{T}$ cells. Interestingly, one major difference between SM3-CAR-T tumor and pSM3CAR-T tumor was positive TIA-1 expression in SM3-CAR$\mathrm{T}$ tumor but not in pSM3-CAR-T tumor, which may be contributed by co-expression of IL-12 molecule in SM3CAR-T tumor. Impressively, significant necrosis event was observed in pSM3-CAR-T tumor as shown in circled and arrowed upper left panel of Figure 6A. We also examined

Table 1 Representative blood test results

\begin{tabular}{|c|c|c|c|c|c|c|}
\hline Item & Before treatment & Post treatment day 1 & Post treatment day 5 & Post treatment day 20 & Post treatment day 26 & Normal range \\
\hline Eosinophil ratio & $14.3 \%$ & $6 \%$ & $14 \%$ & $11.7 \%$ & $12.9 \%$ & $0.4 \%-0.8 \%$ \\
\hline Eosinophil counts & 0.70 & 0.48 & 0.88 & 0.73 & 0.88 & $0.02-0.52$ \\
\hline $\mathrm{PO}_{4}^{-}$ & 1.26 & 1.17 & 1.52 & 1.18 & 0.75 & $0.81-1.45$ \\
\hline Urea & 5.5 & 4.67 & 6.03 & 5.7 & 2.82 & $3.30-8.22$ \\
\hline Uric & 133 & 281 & 266 & 266 & 137 & $240-490$ \\
\hline $\mathrm{LDH}$ & 162 & 145 & 290 & 148 & 129 & $11-220$ \\
\hline
\end{tabular}



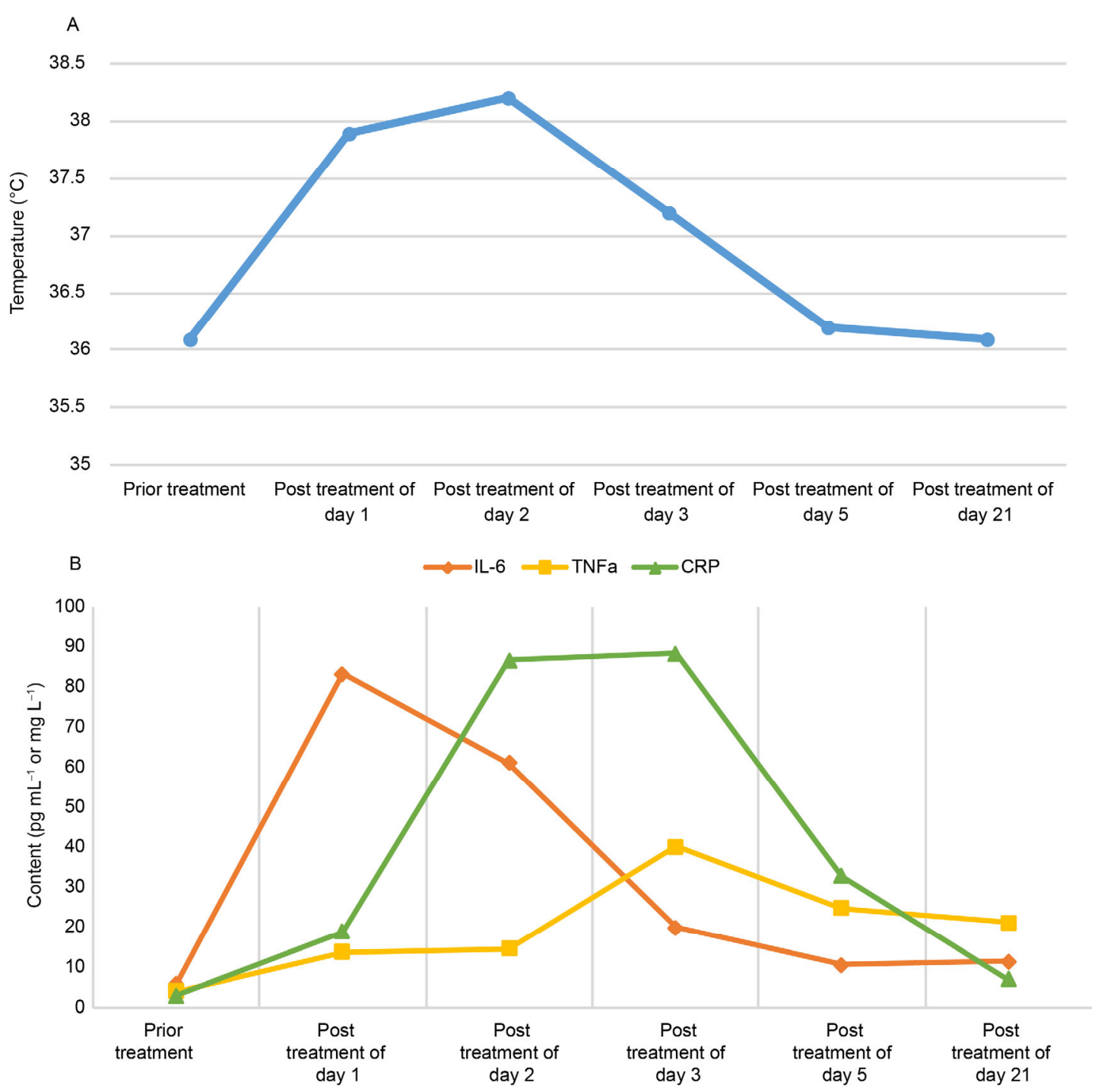

Figure 4 (color online) Patient response to CAR-T treatment. A, Patient body temperature measurement during the CAR-T cells treatment. B, Patient serum cytokines detection during the CAR-T cells treatment. The unit of vertical ordinate for IL-6 and TNF $\alpha$ is pg mL $\mathrm{mL}^{-1}$, for CRP is $\mathrm{mg} \mathrm{L}^{-1}$.

Table 2 Histopathological analysis of resected tumors

\begin{tabular}{|c|c|c|}
\hline Item & SM3-CAR-T-treated tumor & pSM3-CAR-T-treated tumor \\
\hline Morphology & $\begin{array}{l}\text { Aggregated tumor cells nested in fibrous connective tis- } \\
\text { sue, with adenocarcinoma invasion/metastasis }\end{array}$ & $\begin{array}{l}\text { Aggregated tumor cells nested in fibrous connective tissue, } \\
\text { with adenocarcinoma invasion/metastasis }\end{array}$ \\
\hline Tumor necrosis & Little necrosis & Significant multiple necrotic foci \\
\hline Infiltration event & Lymphocytic mononuclear cell infiltration & Lymphocytic mononuclear cell infiltration \\
\hline Hemorrhage & Some & Some \\
\hline Fibrosis & Positive & Positive \\
\hline $\begin{array}{l}\text { Major infiltrating immune } \\
\text { cells }\end{array}$ & $\begin{array}{l}\mathrm{CD}^{+} / \mathrm{CD}^{+}{ }^{+} \mathrm{T} \text {-cells, } \mathrm{CD} 8^{+} \text {mononuclear cells, and } \mathrm{Fc}^{+} \\
\text {CAR-T cells }\end{array}$ & $\begin{array}{l}\mathrm{CD}^{+} / \mathrm{CD}^{+}{ }^{+} \text {T-cells, } \mathrm{CD} 68^{+} \text {mononuclear cells, and } \mathrm{Fc}^{+} \\
\text {CAR-T cells }\end{array}$ \\
\hline $\begin{array}{l}\text { Minor infiltrating immune } \\
\text { cells }\end{array}$ & $\mathrm{CD}^{+}$T-cells, $\mathrm{CD}^{+} 6^{+} / \mathrm{Granzyme} \mathrm{B}^{+}$cells, $\mathrm{CD} 20^{+}$cells & $\mathrm{CD}^{+} \mathrm{T}$ cells, $\mathrm{CD}^{+} 6^{+} / \mathrm{Granzyme}^{+}$cells, $\mathrm{CD} 20^{+}$cells \\
\hline TIA positive cells & Yes & No \\
\hline B-cell phenotype & $\mathrm{CD} 20^{+}, \mathrm{CD} 19^{-}$ & $\mathrm{CD} 20^{+}, \mathrm{CD} 19^{-}$ \\
\hline Tumor cell phenotype & $\mathrm{MUC1}^{+}$ & $\mathrm{MUC1}^{+}$ \\
\hline
\end{tabular}

the MUC1 expression in the tissue sections. Majority of pSM3-CAR-T tumor cells lose MUC1 expression, indicating an event of apoptotic tumor cells. A few pSM3-CAR-T tumor cells showed MUC1 positive staining but without nuclei staining (Figure 6C), suggesting that those are dying tumor cells. $\mathrm{CD}^{+}$and $\mathrm{CD} 8^{+} \mathrm{T}$ cells were observed in both 

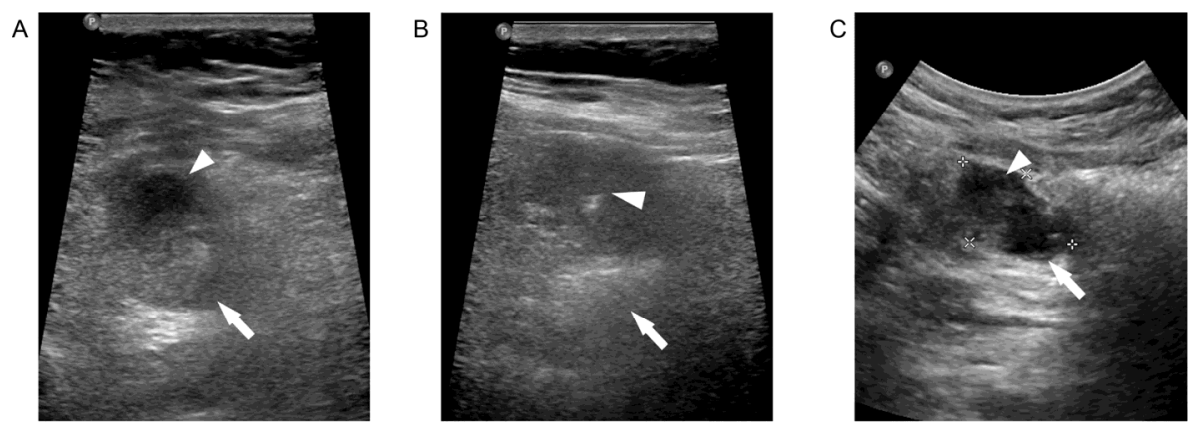

Figure 5 Ultrasonographic images of the metastatic lesions of seminal vesicle carcinoma. A, Grayscale ultrasound illustrated a well defined heterogeneous tumor lesion measuring $3.2 \mathrm{~cm} \times 2 \mathrm{~cm}$ at the upper abdomen. The echolucent area (arrow head) indicated necrosis inside the tumor before treatment. The hypoechoic area (arrow) was selected for the injection of CAR-T cells. B, A 23G needle was used for the injection. With the guidance of real time ultrasound, the needle was precisely inserted in the targeted area. The arrow head represented the insertion point of needle tip. The arrow indicated a convex echogenicity caused by injectd CAR-T cells. C, $21 \mathrm{~d}$ after the injection of CAR-T cells, grayscale ultrasound showed that the injected area became anechoic (arrow), suggesting necrosis of the tumor cells.
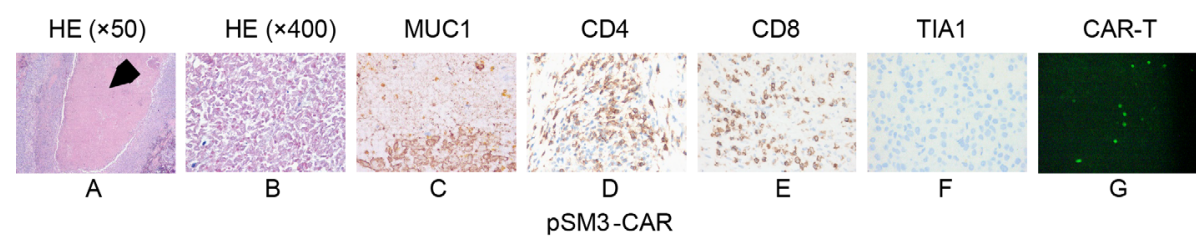

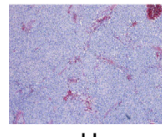

$\mathrm{H}$
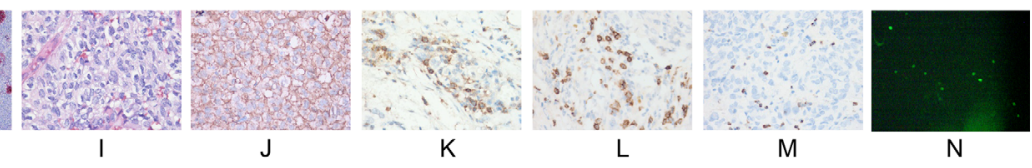

SM3-CAR

Figure 6 Characterization of CAR-T cell treated biopsies. pSM3-CAR tumor showed prominent necrosis of the tumor cells (A, B, arrowed), which were MUC $-1^{+}$(as could be appreciated from the immuno-positivity of viable tumor cells around necrotic debris, C), together with more prominent lymphocytic infiltrates, mostly of $\mathrm{CD}^{+}$(D) or $\mathrm{CD}^{+}$(E) T cells, but not TIA-1 $1^{+}$cell (F). Necrosis was not observed in SM3-CAR tumor (H, I), the cells of which were also $\mathrm{MUC}_{-1}^{+}(\mathrm{J})$, but $\mathrm{CD} 4^{+}(\mathrm{K})$ and $\mathrm{CD}^{+}(\mathrm{L}) \mathrm{T}$ cells were also present inside or around tumor cell nests, although to a lesser extent in comparison to pSM3-CAR tumor (D, E). Scattered TIA- $1^{+}$cells were also observed in SM3-CAR tumor (M). Existence of CAR-T cells were demonstrated in frozen biop$\operatorname{sies}(\mathrm{G}, \mathrm{N})$.

biopsies (Figure 6D, E, K and L), demonstrating persistence of CAR-T cells, which was further supported by anti-Fc staining on frozen tissue sections (Figure $6 \mathrm{G}$ and $\mathrm{N}$ ).

\section{DISCUSSION}

CAR-T cell immunotherapy has shown great antitumor potential in patients with hematologic malignancies in many trials, especially in ALL (Maude et al., 2014). However, antitumor effects of CAR-T cell approaches in solid malignancies were disappointing. This was, in part, due to off-tumor on-target toxicities, as has been observed in CAR-based clinical studies that have targeted carbonic anhydrase IX (CAIX), which is overexpressed in renal cell carcinoma but also expressed at low levels in normal tissues, including the liver (Lamers et al., 2013). The first lethal case in CAR-T therapy involved a patient with colon cancer that has metastasized to the lungs and the liver and was refractory to multiple standard treatments. The patient with ERBB2 (receptor tyrosine-protein kinase erbB-2)overexpressing tumors underwent a third-generation CAR therapy based on the widely used humanized mAb trastuzumab (herceptin). The patient received $10^{10} \mathrm{CAR}-\mathrm{T}$ cells intravenously, but experienced respiratory distress within $15 \mathrm{~min}$ of the infusion, developed a dramatic pulmonary infiltrate (detected in chest X-ray image after 40 min of completion of the infusion), and died five days after treatment. It has been postulated that death resulted from the transfer of highly active anti-ErbB2- directed T-cells. Upon first-pass clearance in the lung, these cells recognized ErbB2 expressed by normal lung cells, and released inflammatory cytokines (including TNF- $\alpha$ and IFN- $\gamma$ ) that caused pulmonary toxicity and edema. This was followed by a cascading cytokine storm and resulted in multi-organ failure, similar to the multiple organ dysfunction syndrome caused by a variety of acute physiological insults (e.g., trauma or severe infections) (Morgan et al., 2010).

Another obstacle in CAR-T therapy of solid malignances is the immunosuppressive microenvironment created by tumor cells, which impairs the CAR-T cell homing ability. T-cell homing is an outcome of an as-yet incompletely understood interplay of a wide range of molecular interactions, 
and great efforts are invested to delineate the molecular mechanisms that underpin this phenomenon. The chemokine system may play a major part in driving T-cell migration and the expression of specific chemokine receptors can aid the precise trafficking of T-cells to tumors. Examples include co-expression of CXCR2 to encourage engineered T-cell migration towards melanoma (Lutschg et al., 2011), and CCR2b expression for T-cell migration towards neuroblastoma (Craddock et al., 2010). In addition, with respect to the immunosuppressive nature of the tumor milieu, TGF- $\beta$, a candidate suppressive cytokine produced by tumor cells, represses the proliferation of both $\mathrm{CD}^{+}$and $\mathrm{CD} 8^{+} \mathrm{CAR}-\mathrm{T}$ cell subsets but does not repress IFN- $\gamma$ secretion of CAR-T cells or specific CAR-T cell cytolytic activity. CD28 co-stimulation overcomes the TGF- $\beta$-mediated repression of T-cell proliferation (Koehler et al., 2007), reflected by a more pronounced killing of tumor cells. Furthermore, in a CD28-CD3ל CAR, deletion of the lymphocyte-specific protein kinase (LCK) binding site in the CD28 endodomain could improve anti-tumor activity of the CAR-T cells even though Treg cells are present in the tumor lesion (Kofler et al., 2011). Thus, CARs with the modified CD28 endodomain are expected to expedite the implementation of CAR-T cell therapy in patients whose tumors are heavily infiltrated by Tregs. CAR-T cell-mediated recruitment of other components of the immune system and their involvement in an antitumor response represent another key aspect of improving the therapeutic efficacy of CAR-T cells. Experiments with constructs comprising the CAR expression vector and a responsive cytokine gene expression-driving promoter have demonstrated that CAR-T cells can produce high levels of cytokines upon antigen binding. Indeed, studies have shown that therapy with CAR-T cells engineered to release IL-12 result in an enhanced recruitment of innate immune cells and reinforcement of their functions (Pegram et al., 2012; Chmielewski and Abken, 2015). Notably, Chmielewski et al. showed that IL-12 secretion induced upon CAR engagement resulted in the destruction of antigen-negative cancer cells that would normally escape the T-cell therapy (Pegram et al., 2012; Chmielewski and Abken, 2015). The above-mentioned reports indicate that Th1-driving cytokines, such as IL-12, can muster a macrophage response towards tumor cells that have ceased tumor antigen expression, in otherwise inaccessible tumor lesions, in a manner associated with a localized proinflammatory response and reduced systemic toxicity. It is important to identify whether other cytokines or immune-potentiating molecules can strengthen and fine-tune the overall patient immune response towards solid tumors, thereby amplifying the antitumor effect driven by the CAR-T cells and to establish an immunological memory to challenge recurrence of the tumor.

Given the above-mentioned reasons, it is critical to consider potential off-target toxicities and strategies that mitigate these toxicities in the early clinical developments of
CAR-T cell solid malignancies approaches. Here, we have shown the feasibility of employing CAR-T cells using a mutated anti-MUC1 scFv (pSM3) construct based on SM3 sequence. We have explored the safety and bioactivity of MUC1-redirected CAR-T cells in a patient with advanced seminal vesicle carcinoma. MUC1 is a well-established tumor associated antigen (TAA), which is abnormally expressed in a variety of cancer cells, predominantly epithelial tumors (Jonckheere and Van Seuningen, 2010). MUC1 is commonly over-expressed in tumor-associated form that has been predicted to be a potential target of immune therapy for about $80 \%$ of all cancer cases (Kimura and Finn, 2013). It is also expressed in normal tissues (Peat et al., 1992), albeit as a different glycoform. It is noteworthy that the first detailed report of T-cell response to MUC1 in humans was very unusual in that the T-cells were not specific to MUC1 peptide sequences within the target surface MHC I (Barnd et al., 1989). Rather, they were MHC I-unrestricted and were specifically blocked by SM3 antibody raised against MUC1 protein core. Therefore, we chose SM3 scFv sequence as our initial candidate for constructing CAR-T cells. However, a previous report indicated that SM3 binding to tumor-associated glycoforms of MUC1 was inadequate (Wilkie et al., 2008). Therefore, Wilkie et al. developed a modified $\mathrm{scFv}$ construct that improved the retargeting capacity of tumor-associated MUC1-specific CAR (Wilkie et al., 2008). We mutated six amino acids in the SM3 $\mathrm{scFv}$ sequence to mimic HMFG2, and with further optimization, we obtained an artificial $\mathrm{scFv}$ sequence of pSM3. Our findings show that the safety of pSM3-CAR-T cells was acceptable for intratumoral delivery, by injection, and mediated antitumor activity in vivo, including the induction of epitope spreading. We detected evidence of antitumor activity despite no pretreatment lymphodepletion. Meanwhile, although SM3-CAR-T cells showed cytotoxicity toward T47D cells in vitro, they failed to kill the patient's tumor cells in vivo even though IL-12 was artificially co-expressed with SM3-CAR. This suggested that the scFv element plays a vital role in CAR-T cell therapy.

We designed two types of CAR-T constructs to evaluate the safety and efficacy of CAR-T cells. One, SM3-CAR, was predicted to bind tumor-associated MUC1 poorly, but the constructed cell line co-expressed IL-12. We hypothesized that IL-12 would play a major role against tumor cells if the engineered CAR-T cells would not be able to fully recognize their tumor target. The other CAR, pSM3-CAR, comprised a mutated SM3 scFv sequence to improve its binding to tumor-associated MUC1 in the absence of engineered IL-12 co-expression. This experimental approach was designed to demonstrate the role of tumor antigen targeting in a cancer patient treatment. We observed little therapeutic benefits when using SM3-CAR-T cells, but an obvious anti-tumor activity exerted by pSM3-CAR-T cells, suggesting that a careful choice of the target antigen, and the appreciation of its accessibility and expression levels, 
must be considered in future proposals of CAR-T cell clinical trials.

However, target antigen selection and CAR-T cell intratumoral injection constitute only the first step toward treatment and cure of solid tumors. Considerable challenges still remain for CAR-T cell therapy. For example, given the long timeline of tumorigenesis, most solid tumors are invariably less oxygenated than normal tissues from which they arose. This so-called tumor hypoxia leads to resistance to radiotherapy and anticancer chemotherapy, as well as predisposes to increased tumor metastases (Dhani et al., 2015). Accordingly, even though CAR-T cells are injected intratumorally, tumor hypoxia is expected to affect CAR-T cell viability, which in turn will seriously reduce their therapeutic efficacy. As part of a solution to this problem, we are developing new strategies, such as normalizing blood supply to the tumor prior to CAR-T cell injection.

Development of immunotherapy against MUC1 raises two additional concerns. First, MUC1 is expressed at lower levels by several normal tissues. Nonetheless, this did not interfere in Ab-based therapeutic protocols targeting this antigen (Taylor-Papadimitriou et al., 2002; Beatson et al., 2010; Kimura and Finn, 2013). Cells of a non-tumorigenic mammary cell line were not killed by CAR-T cells despite low-level expression of MUC1, according to another report. This may reflect the predominance of core two glycans on MUC1 in non-transformed cells (Dalziel et al., 2001; Mungul et al., 2004; Tarp et al., 2007; Blixt et al., 2011; Beatson et al., 2015) that inhibit HMFG2 binding (Wilkie et al., 2008). Together, these reports are reassuring when considering clinical risks posed by MUC1-targeting T-cells. A second concern of Ab-based immunotherapy comprises reduced efficacy due to binding of soluble antigen targets. The polyvalent nature of MUC1 raises the probability that $\mathrm{Ab}$ binding might produce large circulating immune complexes, leading to immunopathology. However, binding of soluble MUC1 may favor the CAR-based approach, facilitating tumor-dependent T-cell expansion and persistence. Such a mechanism has been implicated in the in vivo efficacy of CAR-grafted T-cells against B-cell tumors (Correa et al., 2003). We did not detect any apparent evidence of off-tumor toxicities accompanying the CAR-T cell dosage or intratumoral delivery used in our study, although blood was found in the patient's stools after the patient consumed cleansing intestinal phosphate fluid. This suggested that the mutated SM3 scFv sequence (pSM3 scFv) provides a safer approach targeting cancer-associated MUC1.

Some interesting pathological observations were made during this trial. First, the treated tumor biopsies were predominantly infiltrated with the $\mathrm{CD} 8^{+} \mathrm{T}$-cells, with fewer $\mathrm{CD} 4^{+} \mathrm{T}$-cells. Increasing evidence supports the existence of elevated Treg numbers in solid tumors and hematologic malignancies. Tregs, first identified by Sakaguchi (Sakaguchi et al., 2006), mediate peripheral tolerance to self and innocuous environmental antigens. Originally characterized as $\mathrm{CD} 4{ }^{+} \mathrm{CD} 25^{+}$lymphocytes, they also express the forkhead/winged helix family transcription factor FoxP3. This is critical for both the development of Tregs and for their suppressive capacities, and, to an extent, has enabled improved characterization of these cells (Oleinika et al., 2013). Since we used the aAPC (artificial antigen presenting cells) approach to prepare CAR-T cells, which resulted in $\mathrm{CD}^{+}$-dominated CAR-T cells, the observation of few $\mathrm{CD}^{+}$ $\mathrm{T}$-cells and numerous $\mathrm{CD} 8^{+} \mathrm{T}$-cells in the biopsies suggested that the infiltrating T-cells were CAR-T cells, which was further supported by immunostaining with Fc antibody (data not shown). Second, we found one major difference between biomarker expression by SM3-CAR-T- treated tumor and pSM3-CAR-T-treated tumor, namely, the former was TIA-1 positive while the latter was TIA- 1 negative. TIA-1 is an intracellular cytotoxic lymphocyte protein that is localized within cytoplasmic granules containing serine proteases. It is a $15-\mathrm{kD}$-granule membrane-associated protein that can induce apoptotic cell death when introduced into permeabilized cells (Gross et al., 2001). Anti-TIA-1 MAbs detect a subpopulation of $\mathrm{CD}^{+} \mathrm{T}$ - and NK cells that have cytotoxic activity. Our observation could be partially explained by contributions of IL-12 to TIA-1 expression, since we induced IL-12 expression in SM3-CAR-T-treated tumor and IL-12 may recruit and activate NK cells and repel anergic TILs.

Overall, our findings of tumor necrosis induced by pSM3-CAR-T cells have significant implications for the role of CAR therapy in treating MUC1 positive carcinomas. The clinical activity, intervention treatment strategy, and an improved scFv-targeting of tumor-associated MUC1 suggest that CAR-T cell therapy is a promising treatment modality for patients with solid malignancies.

\section{MATERIALS AND METHODS}

\section{Patient background}

Patient\#2 had an advanced left seminal vesicle cancer with extensive metastasis, and was enrolled into a clinical trial at the Suzhou Kowloon Hospital with the approval of The Ethics Committee of the Hospital. Written informed consent was obtained before the trial. This patient was first diagnosed with left seminal vesicle cancer in 2006.

The last spiral CT scan of this patient was performed on February 25, 2015, and included chest, abdomen, and pelvis. When compared to an earlier CT scan from October 6, 2014, the sizes of most metastatic lesions increased, some were unchanged, and some decreased. In the increased size lesions, the right upper lobe pleural implant increased from $2.1 \times 1.2 \mathrm{~cm}^{2}$ to $3.4 \times 1.8 \mathrm{~cm}^{2}$. Dated pleural implant seen in the right paravertebral region increased from 1.9 to $2.4 \mathrm{~cm}$. An implant seen in the right lower lobe increased from 1.2 to $1.9 \mathrm{~cm}$. Pleural nodularity involving the right major fissure was also more prominent when compared to the earlier CT scan. 
The metastatic lesions whose sizes decreased included left supraclavicular lymph node that was measured as $2.5 \times 1.9 \mathrm{~cm}^{2}$, compared with $2.9 \times 2.2 \mathrm{~cm}^{2}$ in the earlier CT scan, and an implant on the right middle lobe minimally decreased in size from 1.5 to $1.4 \mathrm{~cm}$.

The majority of metastatic lesions were slightly bigger when compared with an earlier CT scan from December 23, 2014. Left para-aortic metastatic lesion increased from $2.1 \times 1.9 \mathrm{~cm}^{2}$ to $2.3 \times 2.2 \mathrm{~cm}^{2}$. A metastatic lesion adjacent to the body of the pancreas increased from $2.0 \times 1.4 \mathrm{~cm}^{2}$ to $2.6 \times 1.7 \mathrm{~cm}^{2}$. Metastatic lesion in the interaortocaval region increased from $3.3 \times 1.9 \mathrm{~cm}^{2}$ to $3.3 \times 2.4 \mathrm{~cm}^{2}$. Metastatic lesion adjacent to the transverse colon increased from $1.9 \times 1.2$ $\mathrm{cm}^{2}$ to $2.3 \times 1.6 \mathrm{~cm}^{2}$. An additional interaortocaval lymph node lesion increased from $1.6 \times 1.2 \mathrm{~cm}^{2}$ to $1.8 \times 1.4 \mathrm{~cm}^{2}$. A metastatic lesion adjacent to the left renal hilum increased from $1.4 \times 1.3 \mathrm{~cm}^{2}$ to $2.0 \times 1.6 \mathrm{~cm}^{2}$.

Some of the metastatic lesions were stable, e.g. one lesion adjacent to the right kidney measuring $1.8 \times 1.3 \mathrm{~cm}^{2}$.

The patient's spleen was resected. Overall, no significant change was observed in the appearance of the dilated bile duct system. Some atrophy of the left kidney was detected, but no bilateral hydronephrosis was found. Surgical changes of colorectal anastomosis in the pelvic region were apparent, with no overall significant change in soft tissue mass in the prostatic bed region.

\section{Clinical protocols}

Phase I clinical trial (NCT02587689) was designed to evaluate the manufacturing feasibility and safety of MUC1CAR-T cells in patient with advanced seminal vesicle carcinoma. The patient received two intratumoral injections of SM3-CAR-T and pSM3-CAR-T cells into two separate tumor lesions respectively, where one mass has a size of 38.1 $\mathrm{mm} \times 23.7 \mathrm{~mm}$ located at right upper outer quadrant and another lesion is of $33.6 \mathrm{~mm} \times 22.8 \mathrm{~mm}$ located at inferior the xiphoid process region, demonstrated by axial CT (Figure S1 in Supporting Information). Both lesions received a dosage of $5 \times 10^{5}$ CAR-T cells, followed by serum cytokines monitoring. $21 \mathrm{~d}$ later after completing this treatment, grayscale ultrasound analysis and immunohistochemistry assays were performed to evaluate the clinical response.

\section{MUC1-CAR construction}

MUC1-CAR expression cassettes were designed as described in the RESULTS. Briefly, SM3-CAR and pSM3CAR expressing a single chain antibody of SM3, and a mutated single chain antibody of SM3 (pSM3) were constructed, with $\mathrm{T}$ cell activation signal, costimulatory signal, with IL-12 in SM3-CAR, or without IL-12 in pSM3-CAR. The lentiviral vector plasmid of pCDH-CMV-MCS-EF1CopGFP was used as a gene transfer backbone vector.

\section{T cell culture}

$20 \mathrm{~mL}$ of peripheral blood mononuclear cells (PBMC) were separated from patient blood using Ficoll (GE ) and suspended at a concentration of $1 \times 10^{6}$ cells per $\mathrm{mL}$ in $\mathrm{T}$ cell medium. T cells were cultured on 24-well plates with the density of $1 \times 10^{6}$ cells per well and stimulated by pAPC ${ }^{\text {CTL }}$ Kit (PersonGen Biomedicne (Suzhou) Co., Ltd, Suzhou). Briefly, on day 1 (one day after transduction by lentiviruses), the T cells were stimulated with $\gamma$-irradiated aAPCs at a 1:2 T cell/aAPC ratio. aAPCs were added on day 7 during expansion. $100 \mathrm{IU} \mathrm{mL} \mathrm{mL}^{-1}$ of IL-2 (Novoprotein) alone or combined with $30 \mathrm{ng} \mathrm{mL}^{-1}$ IL-21 (IL-21; eBioscience, Inc., USA) were added to the cultures every $48 \mathrm{~h}$ beginning on day 7. CAR-T cells were cultured for $12 \mathrm{~d}$, and viable cells were counted on the basis of trypan blue exclusion. T cells that were not genetically modified were used as control $\mathrm{T}$ cells; these cells were propagated on g-irradiated aAPCs as well.

\section{Lentivirus production}

The packaging cells of $293 \mathrm{~T}$ were maintained in $10 \%$ fetal bovine serum, $1 \%$ penicillin/streptomycin, and $1 \%$ nonessential amino acids in DMEM (Hyclone ) at $37^{\circ} \mathrm{C}$ with $5 \% \mathrm{CO}$. The packaging plasmids were $\Delta \mathrm{R}$, Rev, and VSV-G. Replication-defective lentiviral particles pseudotyped with VSV-G envelope were produced by transient transfection of $293 \mathrm{~T}$ cells with $10 \mathrm{mg}$ of the gene transfer constructs, $6.5 \mathrm{mg}$ of $\Delta \mathrm{R}, 3.5 \mathrm{mg}$ of VSV-G and $2.5 \mathrm{mg}$ of Rev, using transfection reagents. The transfection medium was replaced after $12 \mathrm{~h}$ with fresh culture medium. Viral supernatants were harvested at $72 \mathrm{~h}$ after transfection and filtered through $0.22 \mathrm{~mm}$ filters. Supernatants were either used immediately for transductions or were aliquoted and stored at $-80^{\circ} \mathrm{C}$ until use. Titers of viral supernatants were determined by transducing $293 \mathrm{~T}$ cells with serial dilutions of viral supernatants, followed by flow cytometry analysis of Fc-positive cells, $48 \mathrm{~h}$ after transduction.

\section{Lentiviral transduction}

To determine transduction efficiency, $\mathrm{T}$ cells were used to transduce with lentivirus harvested from 293T cell transfection. T cells $\left(5 \times 10^{5}\right)$ were counted, placed in wells of 24-well plates, and inoculated with lentiviral supernatants above $(\mathrm{MOI}=30)$. The transduced cells were incubated at $37^{\circ} \mathrm{C}$ for $4-6 \mathrm{~h}$, and then the supernatants were removed and replaced with $2 \mathrm{~mL}$ volume of fresh 10\% RPMI-1640 medium (Hyclone, GE Healthcare Bio-Sciences, USA). At $72 \mathrm{~h}$ post-transduction, $\mathrm{T}$ cells were performed $\mathrm{Fc}$ immunostaining and observed by fluorescence microscope qualitatively and analyzed by FACSCalibur (BD Biosciences, USA).

\section{CAR detection on transduced $T$ cells}

Transduced T cells were analyzed using FACSCalibur (BD) 
to determine the Fc-positive cell ratio. Cells were washed and suspended in phosphate-buffered saline (PBS), and subjected to flow cytometry assay.

\section{Cytotoxicity assay}

T47D tumor cell line (purchased from ATCC) that is highly expressing endogenous MUC1 were labeled with CFSE (carboxyfluorescein succinimidyl ester, BD). CFSE-loaded T47D cells were mixed with SM3-CAR-T cells and pSM3-CAR-T cells respectively at a ratio of 5:1 and 30:1, and incubated for $24 \mathrm{~h}$. Untransduced $\mathrm{T}$ cells were served as negative controls. After $24 \mathrm{~h}$ of co-culture, cells were stained with 7-AAD (7-aminoactinomycin D, BD), and the percentage of dead tumor cells (CFSE positive and 7-AAD positive) was determined.

Compliance and ethics Lin Yang and Bozhen Zhang have ownership interest (including patents) at Persongen Biomdicine (Suzhou) Co., Ltd. Fengtao You, Licui Jiang, Yunhui Zong, Lei Huang, Man Lu, Jirong Tang, Yafen Li, Sisi Ye, Dan Chen are employees of Persongen Biomdicine ( $\mathrm{Su}$ zhou) Co., Ltd.

Acknowledgements This work was supported by the Priority Academic Program Development of Jiangsu Higher Education Institutions, the National Natural Science Foundation of China (31471283).

Abken, H. (2015). Adoptive therapy with CAR redirected T cells: the challenges in targeting solid tumors. Immunotherapy 7, 535-544.

Acres, B., Lacoste G., and Limacher J.M. (2015). Targeted immunotherapy designed to treat MUC1-expressing solid tumour. Curr Top Microbiol Immunol doi: 10.1007/82_2015_429.

Acres, B., and Limacher, J.M. (2005). MUC1 as a target antigen for cancer immunotherapy. Expert Rev Vaccines 4, 493-502.

Barnd, D.L., Lan, M.S., Metzgar, R.S., and Finn, O.J. (1989). Specific, major histocompatibility complex-unrestricted recognition of tumor-associated mucins by human cytotoxic T cells. Proc Natl Acad Sci USA 86, 7159-7163.

Barrett, D.M., Teachey, D.T., and Grupp S.A. (2014). Toxicity management for patients receiving novel T-cell engaging therapies. Curr Opin Pediatr 26, 43-49.

Beatson, R., Maurstad G., Picco G., Arulappu A., Coleman J., Wandell, H. H., Clausen, H., Mandel, U., Taylor-Papadimitriou, J., Sletmoen, M., and Burchell J.M. (2015). The breast cancer-associated glycoforms of MUC1, MUC1-Tn and sialyl-Tn, are expressed in COSMC wild-type cells and bind the C-type lectin MGL. PLoS One 10, e0125994.

Beatson, R.E., Taylor-Papadimitriou, J., and Burchell, J.M. (2010). MUC1 immunotherapy. Immunotherapy 2, 305-327.

Blixt, O., Bueti, D., Burford, B., Allen, D., Julien, S., Hollingsworth, M., Gammerman, A., Fentiman, I., Taylor-Papadimitriou, J., and Burchell J. M. (2011). Autoantibodies to aberrantly glycosylated MUC1 in early stage breast cancer are associated with a better prognosis. Breast Cancer Res 13, R25.

Burchell, J., and Taylor-Papadimitriou, J. (1993). Effect of modification of carbohydrate side chains on the reactivity of antibodies with core-protein epitopes of the MUC1 gene product. Epithelial Cell Biol 2, $155-162$.

Chinnasamy, D., Yu, Z., Kerkar, S.P., Zhang, L., Morgan, R.A., Restifo, N.P., and Rosenberg, S.A. (2012). Local delivery of interleukin-12 using $\mathrm{T}$ cells targeting VEGF receptor-2 eradicates multiple vascularized tumors in mice. Clin Cancer Res 18, 1672-1683.

Chmielewski, M., and Abken, H. (2015). TRUCKs: the fourth generation of CARs. Expert Opin Biol Ther 15, 1145-1154.

Chmielewski, M., Hombach, A.A., and Abken H. (2014). Of CARs and TRUCKs: chimeric antigen receptor (CAR) $\mathrm{T}$ cells engineered with an inducible cytokine to modulate the tumor stroma. Immunol Rev 257, 83-90.

Condomines, M., Arnason, J., Benjamin R., Gunset G., Plotkin, J., and Sadelain, M. (2015). Tumor-targeted human $T$ cells expressing CD28-based chimeric antigen receptors circumvent CTLA-4 inhibition. PLoS One 10, e0130518.

Correa, I., Plunkett T., Vlad, A., Mungul, A., Candelora-Kettel, J., Burchell, J.M., Taylor-Papadimitriou, J., and Finn, O.J. (2003). Form and pattern of MUC1 expression on T cells activated in vivo or in vitro suggests a function in T-cell migration. Immunology 108, 32-41.

Craddock, J.A., Lu, A., Bear, A., Pule, M., Brenner, M.K., Rooney, C.M., and Foster, A.E. (2010). Enhanced tumor trafficking of GD2 chimeric antigen receptor $\mathrm{T}$ cells by expression of the chemokine receptor CCR2b. J Immunother 33, 780-788.

Dalziel, M., Whitehouse, C., McFarlane, I., Brockhausen, I., Gschmeissner, S., Schwientek, T., Clausen, H., Burchell, J.M., and Taylor-Papadimitriou, J. (2001). The relative activities of the C2GnT1 and ST3Gal-I glycosyltransferases determine O-glycan structure and expression of a tumor-associated epitope on MUC1. J Biol Chem 276, $11007-11015$.

Davila, M.L., and Brentjens, R. (2013). Chimeric antigen receptor therapy for chronic lymphocytic leukemia: what are the challenges? Hematol Oncol Clin North Am 27, 341-353.

Dhani, N., Fyles, A., Hedley, D., and Milosevic, M. (2015). The clinical significance of hypoxia in human cancers. Semin Nucl Med 45, 110-121.

Gendler, S.J., Spicer, A.P., Lalani, E.N., Duhig, T., Peat, N., Burchell, J., Pemberton, L., Boshell, M., and Taylor-Papadimitriou, J. (1991). Structure and biology of a carcinoma-associated mucin, MUC1. Am Rev Respir Dis 144, S42-S47.

Gheybi, E., Amani, J., Salmanian, A.H., Mashayekhi, F., and Khodi, S. (2014). Designing a recombinant chimeric construct contain MUC1 and HER2 extracellular domain for prediagnostic breast cancer. Tumour Biol 35, 11489-11497.

Granowska, M., Britton, K.E., Mather, S.J., Lowe, D.G., Ellison, D., Bomanji, J., Burchell, J., Taylor-Papadimitriou, J., Hudson, C.R., and Shepherd, J.H. (1993). Radioimmunoscintigraphy with technetium-99m-labelled monoclonal antibody, SM3, in gynaecological cancer. Eur J Nucl Med 20, 483-489.

Granowska, M., Mather, S.J., Jobling, T., Naeem, M., Burchell, J., Taylor-Papadimitriou, J., Shepherd, J., and Britton, K.E. (1990). Radiolabelled stripped mucin, SM3, monoclonal antibody for immunoscintigraphy of ovarian tumours. Int J Biol Markers 5, 89-96.

Gross, T., Wagner, A., Ugurel, S., Tilgen, W., and Reinhold, U. (2001). Identification of TIA $-1^{+}$and granzyme $\mathrm{B}^{+}$cytotoxic $\mathrm{T}$ cells in lichen sclerosus et atrophicus. Dermatology 202, 198-202.

Grupp, S.A., Kalos, M., Barrett, D., Aplenc, R., Porter, D.L., Rheingold, S.R., Teachey, D.T., Chew, A., Hauck, B., Wright, J.F., Milone, M.C., Levine, B.L., and June, C.H. (2013). Chimeric antigen receptor-modified T cells for acute lymphoid leukemia. N Engl J Med 368, 1509-1518.

Hillerdal, V., and Essand, M. (2015). Chimeric antigen receptor-engineered $\mathrm{T}$ cells for the treatment of metastatic prostate cancer. BioDrugs 29, 75-89.

Jensen, M.C., and Riddell, S.R. (2014). Design and implementation of adoptive therapy with chimeric antigen receptor-modified T cells. Immunol Rev 257, 127-144.

Jonckheere, N., and van Seuningen, I. (2010). The membrane-bound mucins: from cell signalling to transcriptional regulation and expression in epithelial cancers. Biochimie 92, 1-11.

Jonnalagadda, M., Mardiros, A., Urak, R., Wang, X., Hoffman, L.J., Bernanke, A., Chang, W.C., Bretzlaff, W., Starr, R., Priceman, S., Ostberg, J.R., Forman, S.J., and Brown, C.E. (2015). Chimeric antigen receptors with mutated IgG4 Fc spacer avoid fc receptor binding and improve $\mathrm{T}$ cell persistence and antitumor efficacy. Mol Ther 23, 757-768.

Kakarla, S., and Gottschalk, S. (2014). CAR T cells for solid tumors: 
armed and ready to go? Cancer J 20, 151-155.

Kimura, T., and Finn, O.J. (2013). MUC1 immunotherapy is here to stay. Expert Opin Biol Ther 13, 35-49.

Koehler, H., Kofler, D., Hombach, A., and Abken, H. (2007). CD28 costimulation overcomes transforming growth factor-beta-mediated repression of proliferation of redirected human $\mathrm{CD} 4^{+}$and $\mathrm{CD}^{+} \mathrm{T}$ cells in an antitumor cell attack. Cancer Res 67, 2265-2273.

Kofler, D.M., Chmielewski, M., Rappl, G., Hombach, A., Riet, T., Schmidt, A., Hombach, A. A., Wendtner, C.M., and Abken, H. (2011). CD28 costimulation Impairs the efficacy of a redirected T-cell antitumor attack in the presence of regulatory $\mathrm{T}$ cells which can be overcome by preventing Lck activation. Mol Ther 19, 760-767.

Kruger, W., Kroger, N., and Zander, A.R. (2000). MUC1 expression in hemopoietic tissues. J Hematother Stem Cell Res 9, 409-410.

Lamers, C.H., Sleijfer, S., van Steenbergen, S., van Elzakker, P., van Krimpen, B., Groot, C., Vulto, A., den Bakker, M., Oosterwijk, E., Debets, R., and Gratama, J.W. (2013). Treatment of metastatic renal cell carcinoma with CAIX CAR-engineered T cells: clinical evaluation and management of on-target toxicity. Mol Ther 21, 904-912.

Lamers, C.H., van Steenbergen-Langeveld, S., van Brakel, M., Groot-van Ruijven, C.M., van Elzakker, P.M., van Krimpen, B., Sleijfer, S., and Debets, R. (2014). T cell receptor-engineered T cells to treat solid tumors: $\mathrm{T}$ cell processing toward optimal $\mathrm{T}$ cell fitness. Hum Gene Ther Methods 25, 345-357.

Lutschg, V., Boucke, K., Hemmi, S., and Greber, U.F. (2011). Chemotactic antiviral cytokines promote infectious apical entry of human adenovirus into polarized epithelial cells. Nat Commun 2, 391.

Madsen, C.B., Wandall, H.H., and Pedersen, A.E. (2013). Potential for novel MUC1 glycopeptide-specific antibody in passive cancer immunotherapy. Immunopharmacol Immunotoxicol 35, 649-652.

Maher, J., and Wilkie, S. (2009). CAR mechanics: driving T cells into the MUC of cancer. Cancer Res 69, 4559-4562.

Maude, S.L., Frey, N., Shaw, P.A., Aplenc, R., Barrett, D.M., Bunin, N. J., Chew, A., Gonzalez,V.E., Zheng Z.,, Lacey, S.F., Mahnke,Y.D., Melenhorst, J.J., Rheingold, S.R., Shen, A., Teachey, D.T., Levine, B.L., June, C.H., Porter, D.L., and Grupp, S.A. (2014). Chimeric antigen receptor T cells for sustained remissions in leukemia. N Engl J Med 371,1507-1517.

Maude, S.L., Shpall, E.J., and Grupp, S.A. (2014). Chimeric antigen receptor T-cell therapy for ALL. Hematology Am Soc Hematol Educ Program 2014, 559-564.

Maude, S.L., Teachey, D.T., Porter, D.L., and Grupp, S.A. (2015). CD19-targeted chimeric antigen receptor T-cell therapy for acute lymphoblastic leukemia. Blood 125, 4017-4023.

Morgan, R.A., Yang, J.C., Kitano, M., Dudley, M.E., Laurencot, C.M. and Rosenberg, S.A. (2010). Case report of a serious adverse event following the administration of $\mathrm{T}$ cells transduced with a chimeric antigen receptor recognizing ERBB2. Mol Ther 18, 843-851.

Mungul, A., Cooper, L., Brockhausen, I., Ryder, K., Mandel, U., Clausen, H., Rughetti, A., Miles, D.W., Taylor-Papadimitriou, J., and Burchell,
J.M. (2004). Sialylated core 1 based O-linked glycans enhance the growth rate of mammary carcinoma cells in MUC1 transgenic mice. Int J Oncol 25, 937-943.

Oleinika, K., Nibbs, R.J., Graham, G.J., and Fraser, A.R. (2013). Suppression, subversion and escape: the role of regulatory $\mathrm{T}$ cells in cancer progression. Clin Exp Immunol 171, 36-45.

Peat, N., Gendler, S.J., Lalani, N., Duhig, T., and Taylor-Papadimitriou, J. (1992). Tissue-specific expression of a human polymorphic epithelial mucin (MUC1) in transgenic mice. Cancer Res 52, 1954-1960.

Pegram, H.J., Lee, J.C., Hayman, E.G., Imperato, G.H., Tedder, T.F., Sadelain, M., and Brentjens, R.J. (2012). Tumor-targeted T cells modified to secrete IL-12 eradicate systemic tumors without need for prior conditioning. Blood 119, 4133-4141.

Pegram, H.J., Park, J.H., and Brentjens, R.J. (2014). CD28z CARs and armored CARs. Cancer J 20, 127-133.

Pegram, H.J., Purdon, T.J., van Leeuwen, D.G., Curran, K.J., Giralt, S.A., Barker, J.N., and Brentjens, R.J. (2015). IL-12-secreting CD19-targeted cord blood-derived $\mathrm{T}$ cells for the immunotherapy of B-cell acute lymphoblastic leukemia. Leukemia 29, 415-422.

Porter, D.L., Levine, B.L., Kalos, M., Bagg, A., and June, C.H. (2011). Chimeric antigen receptor-modified $\mathrm{T}$ cells in chronic lymphoid leukemia. N Engl J Med 365, 725-733.

Sakaguchi, S., Ono, M., Setoguchi, R., Yagi, H., Hori, S., Fehervari, Z., Shimizu, J., Takahashi, T., and Nomura, T. (2006). Foxp $3^{+}$CD $25^{+}$ $\mathrm{CD}^{+}$natural regulatory $\mathrm{T}$ cells in dominant self-tolerance and autoimmune disease. Immunol Rev 212, 8-27.

Tang, C.K., and Apostolopoulos, V. (2008). Strategies used for MUC1 immunotherapy: preclinical studies. Expert Rev Vaccines 7, 951-962.

Tang, C.K., Katsara, M., and Apostolopoulos, V. (2008). Strategies used for MUC1 immunotherapy: human clinical studies. Expert Rev Vaccines 7, 963-975.

Tarp, M.A., Sorensen, A.L., Mandel, U., Paulsen, H., Burchell, J., Taylor-Papadimitriou, J., and Clausen, H. (2007). Identification of a novel cancer-specific immunodominant glycopeptide epitope in the MUC1 tandem repeat. Glycobiology 17, 197-209.

Taylor-Papadimitriou, J., Burchell, J.M., Plunkett, T., Graham, R., Correa, I., Miles, D., and Smith, M. (2002). MUC1 and the immunobiology of cancer. J Mammary Gland Biol Neoplasia 7, 209-221.

Taylor-Papadimitriou, J., D'Souza, B., Burchell, J., Kyprianou, N., and Berdichevsky, F. (1993). The role of tumor-associated antigens in the biology and immunotherapy of breast cancer. Ann N Y Acad Sci 698, 31-47.

Turtle, C.J. (2014). Chimeric antigen receptor modified T cell therapy for B cell malignancies. Int J Hematol 99, 132-140.

Wilkie, S., Picco, G., Foster, J., Davies, D.M., Julien, S., Cooper, L., Arif, S., Mather, S.J., Taylor-Papadimitriou, J. Burchell, J.M., and Maher, J. (2008). Retargeting of human T cells to tumor-associated MUC1: the evolution of a chimeric antigen receptor. J Immunol 180, 4901-4909.

Yang, E., Hu, X.F., and Xing P.X. (2007). Advances of MUC1 as a target for breast cancer immunotherapy. Histol Histopathol 22, 905-922.

Open Access This article is distributed under the terms of the Creative Commons Attribution License which permits any use, distribution, and reproduction in any medium, provided the original author(s) and source are credited.

\title{
SUPPORTING INFORMATION
}

\author{
Figure S1 Axial CT images of targeted tumor lesions.
}

The supporting information is available online at life.scichina.com and link.springer.com. The supporting materials are published as submitted, without typesetting or editing. The responsibility for scientific accuracy and content remains entirely with the authors. 